\title{
Instrument Pilot Course Syllabi: A Content Analysis
}

\author{
David Carl Ison \\ Rocky Mountain College
}

\begin{abstract}
The purpose of this research was to examine syllabi collected from four-year, University Aviation Association (UAA) member schools that offer Title 14 of the CFR Part 141 approved instrument pilot instruction through content analysis. These documents were examined for elements deemed essential by the research literature. This investigation sought to identify the inclusion of course descriptions, learning objectives, the coverage of topics required by regulation, the textbooks and other materials used, course assignments, evaluative tools (e.g. tests, quizzes, papers), instructional methods utilized, statements concerning class policies, and statements of academic integrity. Also, this study sought to determine if instrument pilot courses included contemporary issues, namely global position system navigation, and how this subject is conveyed to students. Instrument pilot course syllabi were found to vary widely on the inclusion of critical elements. Only $28.1 \%$ incorporated all of the recommended items. Few (15.6\%) syllabi complied with Part 141 regulatory requirements for subject/objective coverage. The majority of syllabi $(71.9 \%)$ included GPS instruction however the coverage of the material was very limited.
\end{abstract}

\section{INTRODUCTION}

The importance of syllabi in higher education courses is often overlooked. Syllabi set the tone for the course over the entire semester. These documents convey the expectations of the instructor and the required efforts of students in order to succeed in completing the course (Imasuen, 1999). Syllabi define how an instructor will teach a course, how to contact the instructor, and what types of materials are necessary to study the applicable material. Syllabi delineate the learning outcomes for students and provide a framework of how the semester will progress in terms of assignments, examinations, and other projects (Habanek, 2006). Students prefer to receive this clear guidance, which aids them towards completing the requisite coursework. Yet the motivation behind good syllabus design goes beyond the classroom as these documents often serve as a means of communicating outcomes and assessment for institutional self-study and accreditation (Bers, Davis, \& Taylor, 2000).

Certain minimum standards for the content provided by syllabi are well known in the literature, with a large number of syllabi templates that are available to faculty (Bers, Davis, \& Taylor, 2000). Numerous studies have been conducted in order to identify the most efficacious syllabi in terms of construction and content in general and for specific subject areas (Bers, Davis, \& Taylor, 2000; Bers, Davis, \& Taylor, 1996; Slattery \& Carlson, 2005; Habanek, 2006; Johnson \& Ferguson, 1998; Imasuen, 1999; Wasley, 2008). Within aviation coursework that is governed by Title 14 of the Code of Federal Regulations (CFR) Part 141, there is a need to meld campus and/or department syllabi requirements with those of federal regulations. Therefore, aviation syllabi not only must fulfill the typical communication needs to inform students of what is expected of them, but must include the content areas spelled out in the appropriate appendix of Part 141 (Federal Aviation Administration [FAA], 2009). Also, in today's rapidly changing aviation environment it is necessary for courses to cover advancing technologies so that as students are transformed into the pilots of tomorrow, they are equipped to understand and command the improvements. A prominent example of this is the need of instrument pilots to be able to learn, understand, and operate global positioning system (GPS) avionics, including the Wide Area Augmentation System (WAAS), as well as Area Navigation (RNAV) concepts including RNAV GPS approaches and Required Navigation Performance (RNP) (Peterson, 2008). 
Thus it is of significant interest how well current syllabi convey the obligatory information to students including general course standards, Part 141 requirements, as well the inclusion of recent advances in content. Of particular interest are the syllabi for instrument pilot ground courses, as instrument flying is the backbone of a significant portion of commercial flight operations to which many collegiate aviation students aspire to take part, and it is also one of the most exposed to the rapidly changing technological landscape (FAA, 2008). Unfortunately, no current research exists on instrument pilot course syllabi.

\section{The Importance of Syllabi}

Syllabi are an integral part of learning. They provide a roadmap to an individual course, guiding students to their destination of course completion. The critical importance of syllabi has been identified in several research studies. Bers, Davis, \& Taylor (1996) stated that syllabi "are the most complete description of classes that are made available publicly" (p. 2). Also, these guiding works provide "detail about specific class assignments, tests, classroom practices, grading standards, treatment of absences and tardiness, and course objectives that the instructor aims to achieve” (Bers, Davis, \& Taylor, 1996, p. 2).

Imasuen (1999) stated that "course syllabi and the impact they have in the classroom can provide indicators of what students are expected to do in class.... They are the most detailed descriptions of courses offered and they help to ensure that instructors cover required course content" (p. 8). Imasuen (1999) also noted that syllabi provide vital data necessary to determine if coursework at other institutions fulfill the requirements necessary to allow for the transfer or substitution of credit. Habanek (2006) expounded about the importance of syllabi noting that they allow "faculty members [to] define learning outcomes for students and the methods by which those outcomes will be realized" (p. 62). The syllabus also serves as an agreement or contract of how the course is to be conducted and what responsibilities and obligations will be demanded of students. Syllabi also serve as "a permanent record of curriculum and [are] sometimes considered to have official meaning" (Habanek, 2006, p. 62). Davidson and Ambrose (1994) noted that "students learn more effectively when they understand the faculty members' intentions and expectations about a course" (p. 31). Thus syllabi are not simply tossed aside by students upon receipt students do in fact desire clear instructions and expectations for courses they take.

Evidence also exists that indicates that aviation programs benefit from well constructed syllabi. Johnson and Ferguson (1998) stated that "well-developed performance learning objectives provide the underlying foundation for effective learning" (p. 1). So not only is mention of these objectives within a syllabus necessary, they must be clear and comprehensive to provide the needed guidance to students, faculty, and assessors (Bers, Davis, \& Taylor, 2000; Imasuen, 1999). "Developing clear learning objectives has many advantages for students...the student gains a better understanding of the instructor's expectations and the instructor can actually see the subject matter that has to be taught" (Johnson \& Ferguson, 1998, p. 2). With a well-designed syllabus "student confusion and frustration can be limited or eliminated altogether, making the learning experience an enjoyable process" (Johnson \& Ferguson, 1998, p. 2). In summary, Johnson and Ferguson (1998) noted that "clear learning objectives provide the instructor with a precise roadmap necessary for the instructional process to progress steadily and with coherence throughout the duration of the course" (p. 2).

Slattery and Carlson (2005) stated that "syllabi can be useful in engaging students and creating an effective classroom atmosphere" (p. 159). Detailing the crucial nature of syllabi, Slattery and Carlson (2005) noted that:

A strong syllabus facilitates teaching and learning. It communicates the overall pattern of the course so a course does not feel like disjointed assignments and activities, but instead an organized and meaningful journey.... Syllabi are a ubiquitous part of the teaching process... a syllabus serves seven purposes.

It sets the tone for the course, motivates students to set lofty but achievable 
goals, serves as a planning tool for faculty, structures students' work over the course of the semester, help faculty plan and meet course goals in a timely manner, serves as a contract between faculty and students about what students can expect from faculty and vice versa, and is a portfolio artifact for tenure, promotion, or job applications (p. 159).

It is evident that existing research supports the assumption that syllabi are an essential, functional, and supportive component of the classroom learning process. It is no surprise, then, that the literature has also investigated what is necessary to include within this all-important document.

\section{What Makes a Syllabus a Good Syllabus?}

Johnson and Ferguson (1998) explained that it is necessary to have objectives that are specific versus vague. For example words like know, appreciate, and understand should be avoided and instead be replaced with words such as identify, analyze, and implement, respectively. Slattery and Carlson (2005) discovered that syllabi were either written in a "warm and friendly, formal, condescending, or confrontational" (p. 159) manner. Wasley (2008) noted that research indicates that students are sensitive to the feel or mood of the syllabus. Students reported that "they would be significantly less comfortable approaching the author of [a] 'punishing' syllabus" (Wasley, 2008, A11). Habanek (2006) stated that the syllabus:

should clearly model the accountability agreement between professor and a student by the information it provides. The syllabus should explain how the course has been designed by the professor to facilitate learning and what the professor will do to help all students achieve course goals (p. 62).

It is apparent that clear, concise rules, objectives, and guidance should be built into the syllabus to ensure that it will be successful in augmenting student awareness of course and instructor expectations.

Bers, Davis, and Taylor (1996) provided much more detail concerning what should be included in a syllabus. These authors described the need for a generic school or department-wide syllabus which "provides the basic framework for all sections of that course, is used for articulation and official reports, is relatively general in nature, and helps ensure that all instructors cover required content" (p. 2). Each individual instructor then takes this generic syllabus and molds it to develop a document unique for the individual section. This is where students will find tailored information such as assignments, textbooks, tests, due dates, and policies.

More specifically, Bers, Davis, and Taylor (1996) mentioned eleven essential components to include in syllabi:

(1) course prefix, number, name, and credit for lecture or laboratory hours;

(2) prerequisites;

(3) course description from the catalogue;

(4) learning objectives, or what knowledge and skills the student is expected to acquire in the course;

(5) academic integrity statement...;

(6) outline of topics to be covered in the course;

(7) methods of instruction;

(8) required course practices such as reading, writing in-class or out-of-class assignments, oral presentations, computer use, labs, and fieldwork or clinical assignments;

(9) instructional materials such as textbooks and other reading assignments; 
(10) methods of evaluating student progress, such as tests, assignments, class participation, and other ingredients that could in a student's grades;

(11) other course information about expectations about attendance, class policy on make-up examinations, incomplete assignments, tardiness, and references to support services such as tutoring and important college dates (p. 14).

In a later study, Bers, Davis, and Taylor (2000) expand upon what to include in syllabi: "Well-done syllabi identify learning objectives or expected learning outcomes, enumerate topics or learning activities to be covered, and describe the learning activities in which students will engage. Logical syllabi link these so that they are mutually supportive" (p. 4). Slattery and Carlson (2005) described the "parts of an effective syllabus, which include...identifying information, course description, course goals, ways to meet course goals, grades, schedule, rationale, motivational messages, and university support services" (pp. 160-162).

Even in light of the guidelines described in the literature, studies have indicated that a large number of syllabi do not meet these minimum requirements. A great deal of variability in syllabi content was noted by White (2004) while Okumus and Wong (2007) found that the "contents of [strategic management syllabi] do not really reflect recent and advanced developments in the generic strategy field" (p. 77). Davidson, Garton, and Joyce (2003) noted that only a few of the 25 collected syllabi included crucial items such as the type of instructional method that was to be utilized. Drisko (2008) found that very few of the 48 syllabi collected addressed the necessary course content. Cashwell and Young (2004) discovered that $29 \%$ of the syllabi collected had omitted course objectives. Incomplete, inconsistent, or confusing syllabi can be problematic for students. Yet, as these studies all mentioned, little research exists concerning syllabi for courses in individual areas of study (Cashwell \& Young, 2004; Drisko, 2008; Okumus \& Wong, 2007; White, 2004).

\section{Syllabus Content Specific to Title 14 of the CFR Part 141 Aviation Courses}

Although it is apparent that syllabi play a decisive role in communicating with students and supporting their learning, no studies have been completed on instrument pilot course syllabi. Moreover, no research has occurred to investigate if schools providing ground training under Title 14 of the CFR Part 141 are including the necessary material and objectives within such course syllabi. This is problematic considering that a large number of collegiate aviation programs offer instruction under this part of the regulations (University Aviation Association [UAA], 2008). Appendix C to Part 141 describes, in detail, the required content for any instrument pilot course. This ground training must include:

(1) Applicable Federal Aviation Regulations for IFR flight operations

(2) Appropriate information in the "Aeronautical Information Manual"

(3) Air traffic control system and procedures for instrument flight operations

(4) IFR navigation and approaches by use of navigation systems

(5) Use of IFR en route and instrument approach procedure charts

(6) Procurement and use of aviation weather reports and forecasts, and the

elements of forecasting trends on the basis of that information and personal observation of weather conditions

(7) Safe and efficient operations of aircraft under instrument flight rules and conditions

(8) Recognition of critical weather situations and windshear avoidance

(9) Aeronautical decision making and judgment; and

(10) Crew resource management, to include crew communication and coordination (FAA, 2009, p. 452).

It is certainly logical if not necessary to analyze instrument pilot course syllabi to investigate if they are covering the required material. 


\section{Contemporary Aviation Content Issues}

In addition to Part 141 requirements, instructors may want to include a variety of other subject areas within an instrument pilot course. In particular, especially because of its use within instrument flight, the coverage of contemporary issues such as the Global Positioning System (GPS), Wide Area Augmentation System (WAAS), Area Navigation (RNAV), RNAV GPS approaches, and Required Navigation Performance (RNP) concepts are necessary to develop pilots that are best equipped for the real world. An example of why this burden falls upon instrument pilot course faculty is that "the FAA presently has just a few basic GPS questions in each of their Private, Commercial, Instrument, and Airline Transport pilot written exam data banks" (Quinnette, 2002, p. 2). Although students will likely be exposed to the use of GPS in flight training, it is possible that the lessons provided by instrument pilot course faculty may be the only formal classroom based instruction students receive: "current flight training programs do not adequately incorporate the training of GPS navigation procedures in either their ground or flight training programs" (Quinnette, 2002, p. 5).

Further evidence of the cursory instruction on GPS that does occur is that "of the students receiving GPS training only $6 \%$ are receiving more than 2 hours of GPS specific training in the classroom with more than $50 \%$ receiving less than 1 hour of training" (Quinnette, 2002, p. 58). This is particularly troubling considering that "for IFR, it's never a good idea to use a GPS receiver for primary navigation without being thoroughly familiar with it.... The best way to gain familiarity and proficiency is to take a purposeful, systematic approach to learning about the system" (Peterson, 2008, p. 2). Steuemagle (n.d.) stated that "a substantial commitment to study and practice is required before a pilot can fly IFR GPS in safety and confidence" (para. 1). In a study of the necessary amount of instruction to safely and effectively operate GPS on IFR flights by Casner (2004), the author found that "the results strongly suggest that IFR GPS is not a 'walk-up-and-use' system for pilots at any experience level. Considerable learning and practice are required to achieve proficiency with flying IFR with GPS" (p. 10). All of this is worrisome considering the push for the FAA to move towards GPS based Area Navigation (RNAV) (Bertorelli, 2004).

\section{METHOD}

\section{Purpose}

In light of the importance of syllabi to the conduct of courses and to student learning, in addition to the lack of research that has been conducted on this subject area, this study sought to analyze instrument pilot course syllabi through content analysis. The purpose of this study was to examine syllabi collected from four-year, University Aviation Association (UAA) member schools that offer Title 14 of the CFR Part 141 approved instrument pilot instruction in order to determine how or if these documents communicate course descriptions, learning objectives, the coverage of topics required by regulation, the textbooks and other materials used, course assignments, evaluative tools (e.g. tests, quizzes, papers), instructional methods utilized, statements concerning class policies, and statements of academic integrity. Also, this study sought to determine if instrument pilot courses included contemporary issues and changes, namely instruction on GPS, WAAS, RNAV, RNAV GPS approach procedures, and RNP as well as how this subject matter is conveyed to students.

\section{Research Questions}

The following research questions guided this study:

1. Do instrument pilot course syllabi include items described as essential within the research literature? Specifically, do they include course descriptions, learning objectives, topics covered, 
the textbooks and other materials used, course assignments, evaluative tools (e.g. tests, quizzes, papers), instructional methods utilized, statements concerning class policies, and statements of academic integrity?

1. a. What were the listed topics covered, textbooks and other materials used, course assignments, evaluative tools, and instructional methods utilized?

2. Do instrument pilot course syllabi include the course objectives/topics required by Title 14 of the CFR Part 141?

3. Do instrument pilot course syllabi include training on GPS, WAAS, RNAV, RNAV GPS approaches and RNP?

3. a. How much training is provided on GPS and related concepts?

\section{Participants}

Purposive sampling was utilized in an attempt to ensure homogeneity among syllabi. For this study, only schools that were four-year, UAA member institutions offering Title 14 of the CFR Part 141 approved ground instruction were included. The rationale for this selection was that these types of institutions share similar goals and industry participation. Also, four-year institutions are clearly more similar to one another in comparison to weighing a two-year institution versus a four-year counterpart. In addition, the guidelines of Title 14 of the CFR Part 141 create level ground for coursework, as this regulation standardizes the material that must be covered within the course. Instrument pilot course syllabi were utilized as this type of flying is pivotal in almost all pilot careers and instrument flight is conducted across the spectrum of flying careers and components of the aviation industry (FAA, 2009; 2008).

The most recent Collegiate Aviation Guide ( $5^{\text {th }}$ edition) was utilized to identify schools that were fouryear, UAA member institutions offering Part 141 instruction (UAA, 2008). This search yielded 50 institutions.

\section{Procedure}

Content analysis was employed to examine the collected syllabi. According to Holsti (as cited by Berg, 2007) content analysis is "any technique for making inferences by systematically and objectively identifying special characteristics of messages" (p. 306). Okumus and Wong (2007) stated that content analysis "can provide rich and in-depth accounts on a wide range of topics. It establishes categories and then counts the number of related words, sentences and issues under each category" (p. 81). The appropriateness of content analysis in the study of course syllabi was reinforced by the use of this method in a variety of literature concerning these documents (Bers, Davis, \& Taylor, 2000; Bers, Davis, \& Taylor, 1996; Cashwell \& Young, 2004; Habanek, 2006; Imasuen, 1999; Johnson \& Ferguson, 1998; Okumus \& Wong, 2007; Riffe, Lacy, \& Fico, 2005; Slattery \& Carlson, 2005; Wasley, 2008).

The steps in measurement of data presented by Riffe, Lacy, and Fico (2005) were utilized in the development of the research design for this study. The five steps described by these authors were "develop research hypotheses or questions...examine the existing literature...use good previous measures...create coding instructions, and...create coding sheets for recording data" (Riffe, Lacy, \& Fico, 2005 pp. 91-92).

Following the procedural outline utilized by Okunus and Wong (2007) this study was organized to follow the five different stages: "(1) development of research aims and the research framework, (2) finding and selecting appropriate cases, (3) analyzing documents by following the research framework, 
(4) cross-checking and refining the findings and (5) summarizing and finalizing the findings" (p. 82). As recommended by Creswell (2008), the analysis of data stage began by reading through one example syllabus to get a general idea of "what is this about?" (p. 192). Also, as Berg (2007) suggested, the process of open coding was followed during the initial analysis. Open coding is described as "an unrestricted coding of the data. With open coding, you carefully and minutely read the document line by line and word by word to determine the concepts and categories that fit the data" (Berg, 2007, p. 321). From this initial reading, the construct and organization of course descriptions, learning objectives, the coverage of topics, the textbooks and other materials used, course assignments, evaluative tools (e.g. tests, quizzes, papers), instructional methods utilized, statements concerning class policies, statements of academic integrity, and whether or not GPS instruction was mentioned in the syllabus emerged.

A coding scheme was designed to further analyze the syllabi in a more systematic manner. The method of creating and testing a coding scheme described by Weber (1990) was used as a guide in this process. The first step was to "define the recording units" (Weber, 1990, p. 21) which would, in this case, identify what Berg (2007) stated as the "manifest content (those elements that are physically present and countable)" (p. 308). Both words and themes were utilized as the units of analysis. Berg (2007) stated that "the word is the smallest element or unit used in content analysis. Its use generally results in a frequency distribution of specified words or terms" (p. 312). Words such as "lecture" and "discussion" were used to identify the prevalence of these types of instruction methods. More complex content, such as course objectives, were analyzed thematically as Berg (2007) noted "the theme is a more useful unit to count. In its simplest form, a theme is a simple sentence, a string of words with a subject and a predicate" (p. 312).

The next step described by Weber (1990) was to "define the categories. In creating definitions, investigators must make two basic decisions....The first is whether categories are to be mutually exclusive.... The second choice concerns how narrow or broad the categories are to be" (p. 23). Guidance for the development of initial categories was drawn from the essential components of syllabi as described by Bers, Davis, and Taylor (1996). Procedures used by Rendina-Gobioff et al. (2003) were adopted to create more detailed categories. This required the development of a coding checklist:

During the initial stages of the review process, the checklist was revised and refined to meet the needs and goals of the assessment. Wording was clarified where necessary and indicators were added, combined, or deleted as it became more apparent the appropriateness of individual indicators with respect to the language. The final checklist included... categories....Within each of the...categories..., individual indicators were created to represent the various aspects of the domain (p. 5).

This content was then placed in an all-encompassing codebook the purpose of which was to provide explicit instructions to insure standardization in the research process. This codebook was created with guidance from Neuendorf (2001); Riffe, Lacy, and Fico (2005); and Krippendorff (2004) which called for a comprehensive set of instructions that define all variables in the study, give detailed, specific procedures to follow, and assure standardization among coders involved in the study. The actual structure of the codebook was adopted from MacQueen, McLellan, Kay, and Milstein (2008) which divided the document into "six basic components: the code, a brief definition, a full definition, guidelines for when to use the code, guidelines for when not to use the code, and examples" (p. 32). Further, examples of coding instructions by Drisko (2008), Riffe, Lacy, and Fico (2005), Rendina-Gobioff, et al (2003), and Weston, Gandell, J. Beauchamp, McAlpine, Wiesman, and C. Beauchamp (2001) were used to assist in organizing and writing a thorough set of procedures.

Upon completion of this initial coding scheme, it was used to "test coding on a sample of text" (Weber, 1990, p. 23). Next, the initial reliability of the scheme was evaluated. As Lombard, Snyder-Duch, and Bracken (2004) suggested, this took place informally during coder training and formally in this initial 
coding of a sample of text. Following the completion of these testing procedures, coding rules were revised as necessary.

In addition to the researcher, a coding team of two research assistants was utilized. Each coder was given a copy of the codebook that outlined the specific process with which each was expected to comply. Within the codebook was the aforementioned coding checklist. The researcher then confirmed that each coder understood what was expected of them and thoroughly explained the instructions and checklist. Any confusion or questions were resolved prior to the final steps of the data analysis. The last two steps described by Weber (1990), coding the entire sample and assessing overall reliability, were then completed. Following the guidance of Weber (1990), the entire sample of syllabi was analyzed by the researcher. To calculate intercoder reliability, a random sample of four syllabi (which is slightly above the minimum for reliability testing of ten percent recommended by Lombard, Snyder-Duch, and Bracken, [2004]) was distributed to each of the coding team members for analysis.

\section{RESULTS}

\section{Response Rate}

Emails were sent to the program directors or chairs of each of the 50 programs to request instrument pilot ground course syllabi. Forty of the requests were forwarded to the individual instructor by the program director or chair. The remaining ten requests were responded to directly by the director or chair. From the 50 requests that were sent, 37 syllabi were received resulting in a response rate of $74 \%$. However, five institutions provided instrument instruction over two semesters; therefore such syllabi were combined into single units for the purposes of determining response rate. Thus the actual number of useful responses was 32 syllabi (64.0\%). According to Okumus and Wong (2007), "15 cases can be sufficient for explanatory studies using content analysis" (p. 83), thus the number of responses was deemed to be adequate for the purpose of this study.

\section{Essential Syllabus Items}

Syllabi were analyzed for their inclusion of items considered to be essential by the literature. Specifically, syllabi were examined to identify if they included course descriptions, learning objectives, topics covered, the textbooks and other materials used, course assignments, evaluative tools (e.g. tests, quizzes, papers), instructional methods utilized, statements concerning class policies, and statements of academic integrity. Only nine (28.1\%) syllabi contained all of the recommended elements.

Within the syllabi available for study, $20(62.5 \%)$ provided a course description. Twenty-eight (87.5\%) of syllabi outlined learning objectives however, among these, three (9.4\%) syllabi solely focused on the objective of passing the FAA Instrument Pilot Knowledge Test. The syllabi focused on a variety of topics. A breakdown of the inclusion rates of topics can be found in Figure 1. The most prevalent of topics reported were instrument navigation $(90.6 \%)$, enroute operations $(90.6 \%)$, approach procedures (84.4\%), holding (84.4\%), departures (84.4\%), and basic attitude instrument flying (84.4\%). The topics that were included least were crew resource management $(31.3 \%)$, FAA written test preparation (21.8\%), the AIM (15.6\%), safe and efficient operation of aircraft (12.5\%), and aerodynamics (9.4\%). Six (18.8\%) syllabi reported one or more topics that were not specifically addressed in the coding scheme. These extra topics were aircraft performance $(12.5 \%)$, accidents $(6.3 \%)$, maintenance documentation and regulations $(6.3 \%)$, technically advanced aircraft (3.1\%), and situational awareness (3.1\%).

Twenty-nine $(90.6 \%)$ of syllabi identified what materials would be required for use in the conduct of the class. The most common material identified were texts $(87.5 \%)$. The overwhelming majority of syllabi (84.3\%) noted the Jeppesen Instrument Commercial Manual as the required text. For a complete breakdown of required texts, see Figure 2. Other items identified were maps/charts (34.3\%), videos 


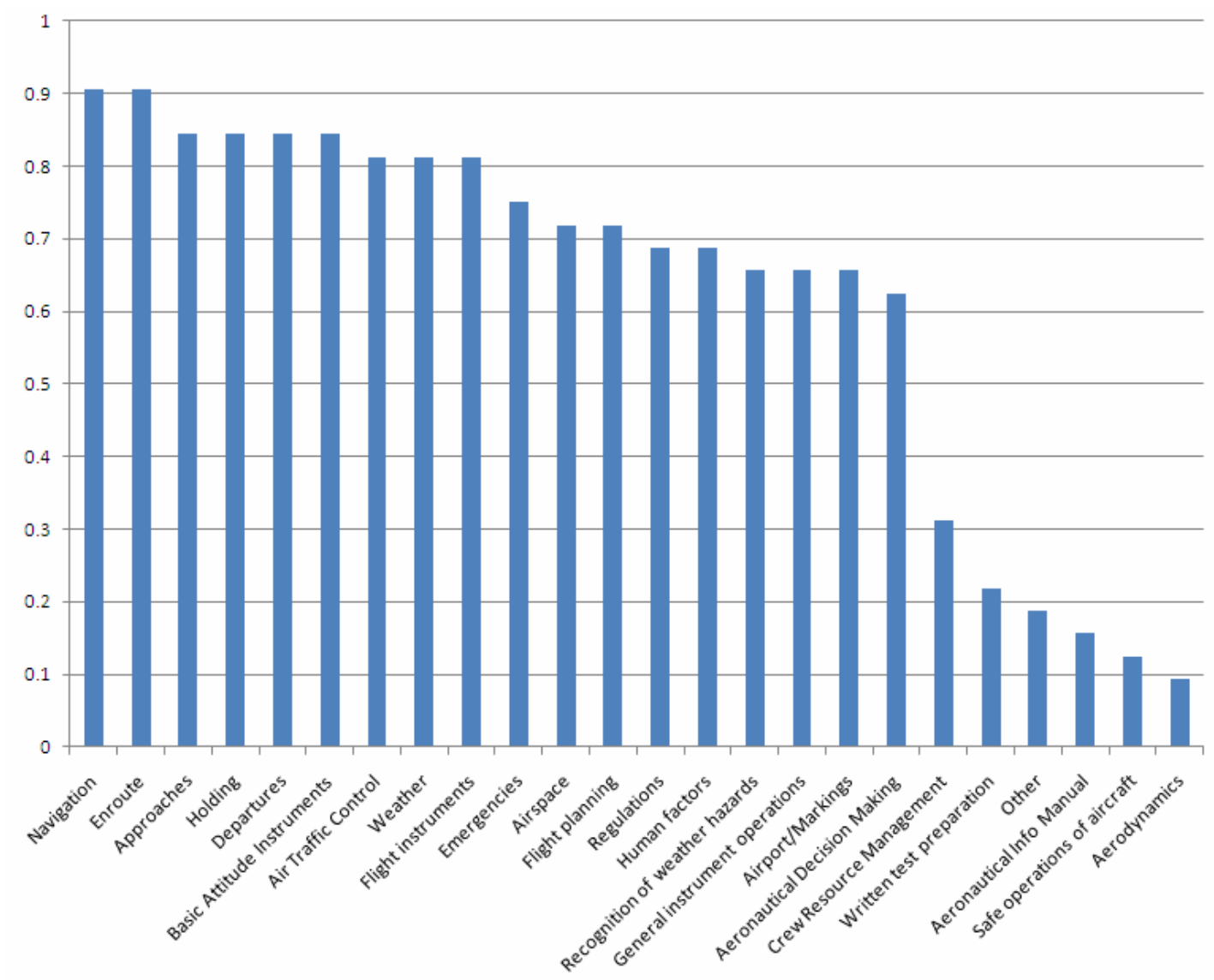

Figure 1. Inclusion rates of instrument pilot course topics.

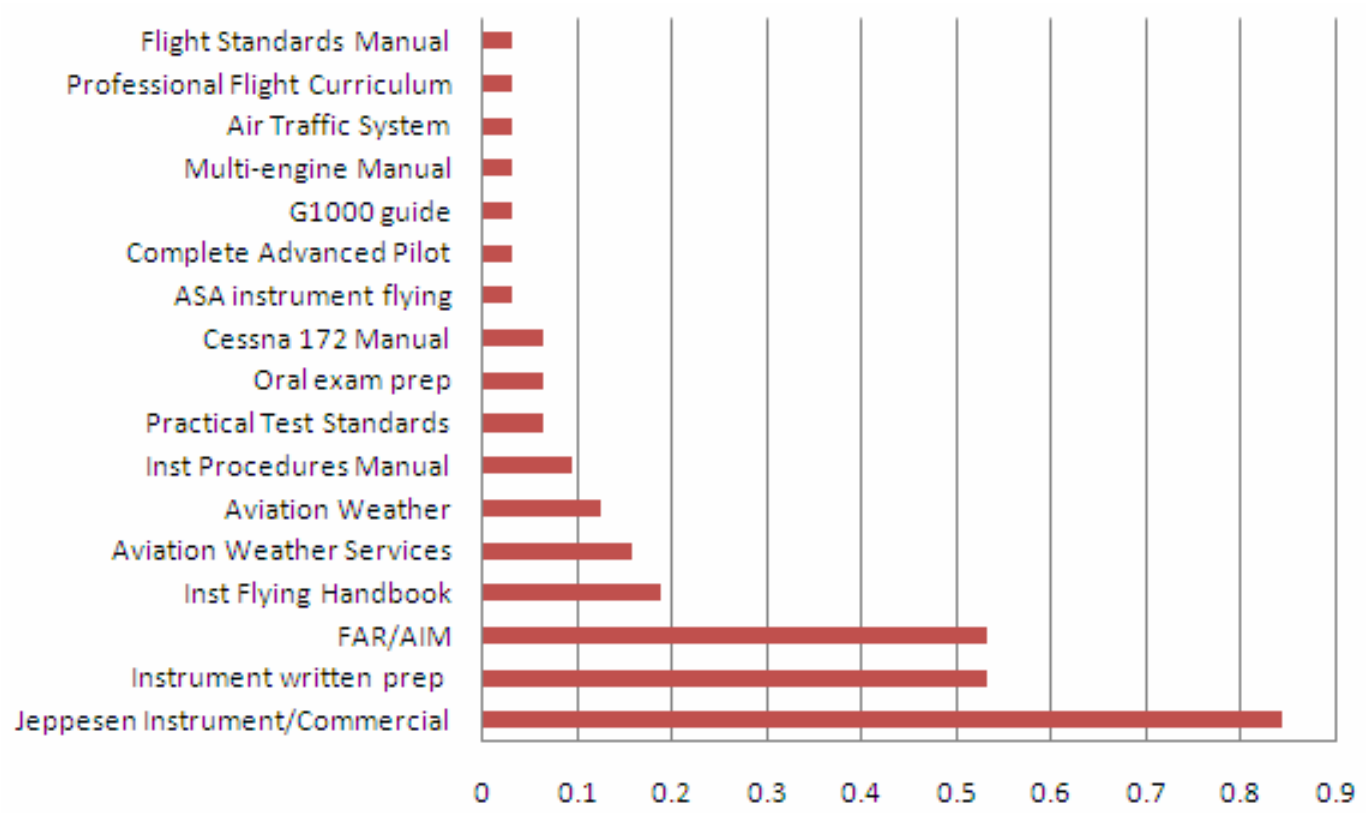

Figure 2. Required texts. 
(9.4\%), computer/simulation (3.1\%) and websites (3.1\%). Seven (21.8\%) of syllabi listed materials that were not specifically addressed on the coding checklist. All of these additional responses indicated the requirement for using flight planning materials (plotters, flight computers, and flight plan forms).

Course assignment types were identified. For the purposes of this study, a course assignment was a task that was dispensed but was not directly measured for inclusion in calculation of the final grade. For example, reading assignments may be required, but are not directly graded and therefore would be included in this category. Items that are assigned but receive a grade were included in the category of evaluative tool. Almost all syllabi (96.9\%) identified reading tasks as course assignments. Writing/article/paper assignments were required in five (15.6\%) syllabi. Computer based exercises/simulation and projects/presentations were each required in three (9.4\%) of syllabi. Two (6.3\%) syllabi identified the FAA written exam as an ungraded assignment. An additional two (6.3\%) syllabi indicated "other" assignments.

Evaluative tools, those items on which students were graded, were noted in all but one (3.1\%) syllabus. The most ubiquitous (29 syllabi or $90.6 \%$ ) tool was the exam/test that was administered during the conduct of the semester/quarter. Quizzes and final exams were each noted as evaluative tools in twenty $(62.5 \%)$ syllabi while attendance was graded in ten $(31.3 \%)$ syllabi. See Figure 3 for a thorough reflection of the evaluative tools identified within the syllabi.

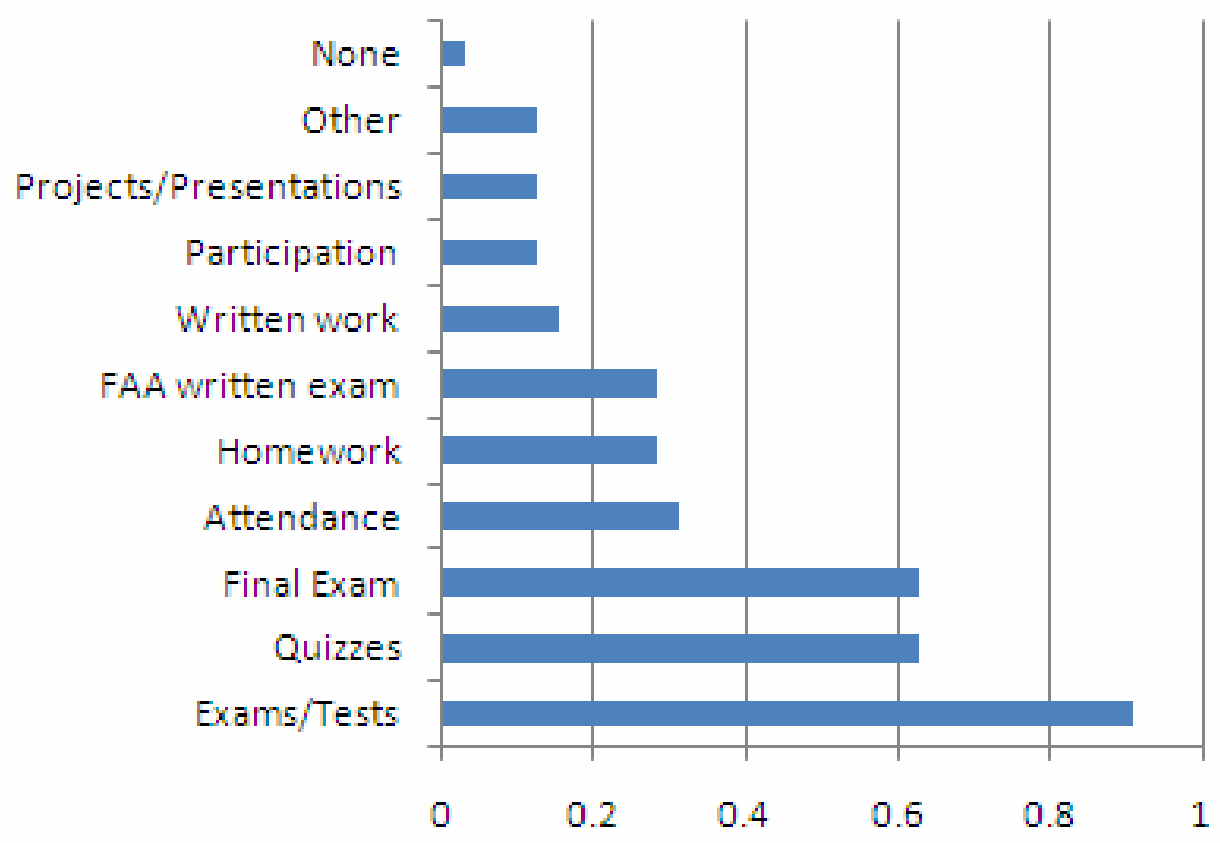

Figure 3. Evaluative tool usage.

Instructional methods were found to be absent from fifteen $(46.9 \%)$ of syllabi. The method used most often was lecture (16 syllabi or $50 \%)$. Video was utilized in nine $(28.1 \%)$ syllabi and discussion was identified in eight $(25 \%)$ cases. The remaining types of instructional methods were online $(12.5 \%)$, computer/simulation $(9.4 \%)$, and laboratory $(6.3 \%)$.

Statements of class policies were indicated in all but one $(3.1 \%)$ syllabus. The policy on attendance/absences was noted in $28(87.5 \%)$ of syllabi. Grading policies and/or grading scales were shown on $25(78.1 \%)$ syllabi. Guidance for students on the course make-up policy was recognized in 21 $(65.6 \%)$ cases. Figure 4 shows all occurrences of class policy statements. Slightly more than half of all 
syllabi (18 or $56.3 \%$ ) had any kind of statement on academic integrity, e.g. the establishment of policy on or definition of cheating, plagiarism, or honor code.

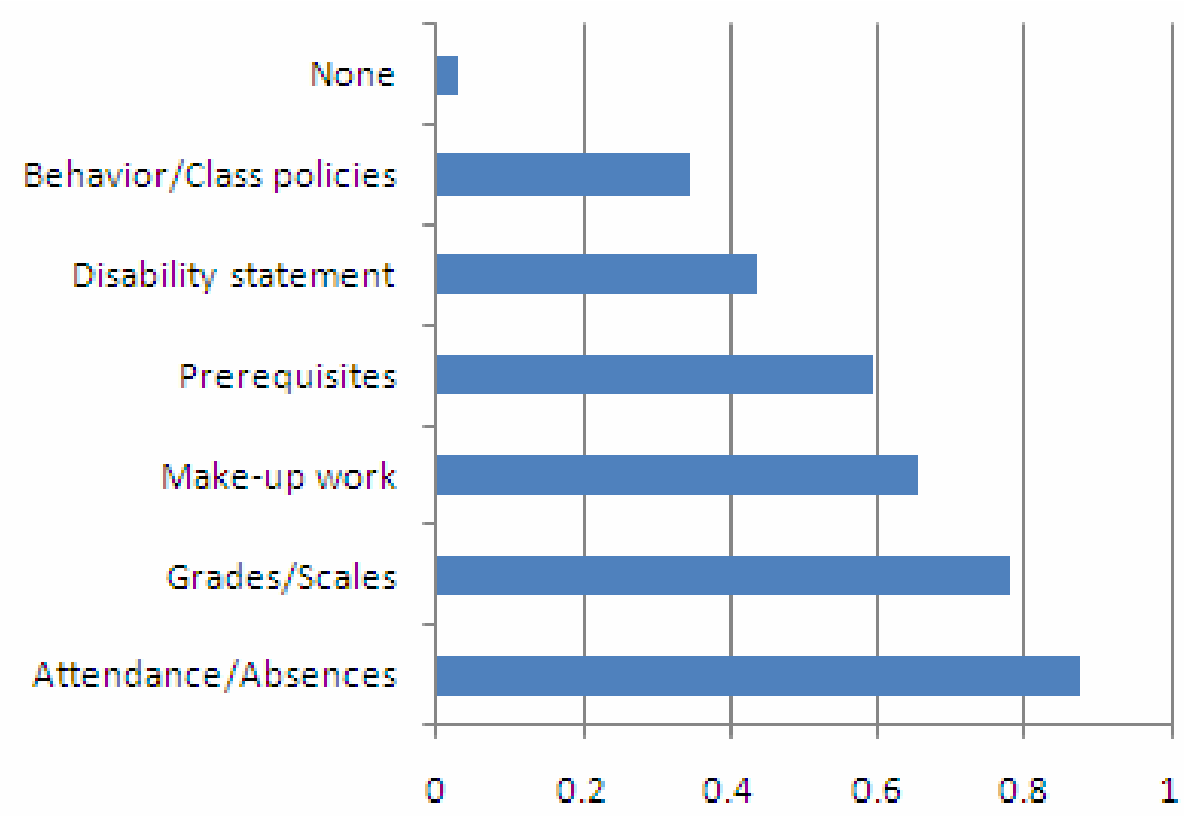

Figure 4. Incidence of class policy statements.

\section{Title 14 of the CFR Part 141 Required Course Objectives/Topics}

Among the 32 syllabi that were analyzed, only five (15.6\%) complied with either the objective and/or content requirements of Title 14 of the CFR Part 141. While many syllabi listed numerous objectives/topics that are required by regulation, there were three commonly omitted subject areas. The most frequently absent was coverage of the Aeronautical Information Manual (AIM) followed by Crew Resource Management (CRM) and "safe and efficient operations of aircraft" (FAA, 2009, p. 452). A comprehensive listing of the percent coverage of subjects required by Title 14 of the CFR Part 141 is shown in Figure 5.

\section{Coverage of GPS Concepts}

Twenty-three (71.9\%) of syllabi reported that GPS would be covered in some form during the course. The mean number of sessions in which GPS was indicated to be covered was $1.30(\mathrm{SD}=0.703)$. Syllabi that indicated that GPS instruction would be included were then analyzed for the type of information that would be conveyed in the lesson(s). Six (18.8\%) syllabi showed that GPS would only be discussed in general terms, such as basic information on how the system works, and applicable regulations. Fourteen (43.8\%) syllabi stated that such instruction would be limited to the general use of GPS for instrument approaches. Only four (12.5\%) covered both general GPS topics and GPS use in approaches. Sixteen $(50.0 \%)$ syllabi included RNAV in general and twelve $(37.5 \%)$ addressed specific RNAV GPS approaches and procedures. Only two (6.3\%) mentioned WAAS and zero syllabi included RNP. 


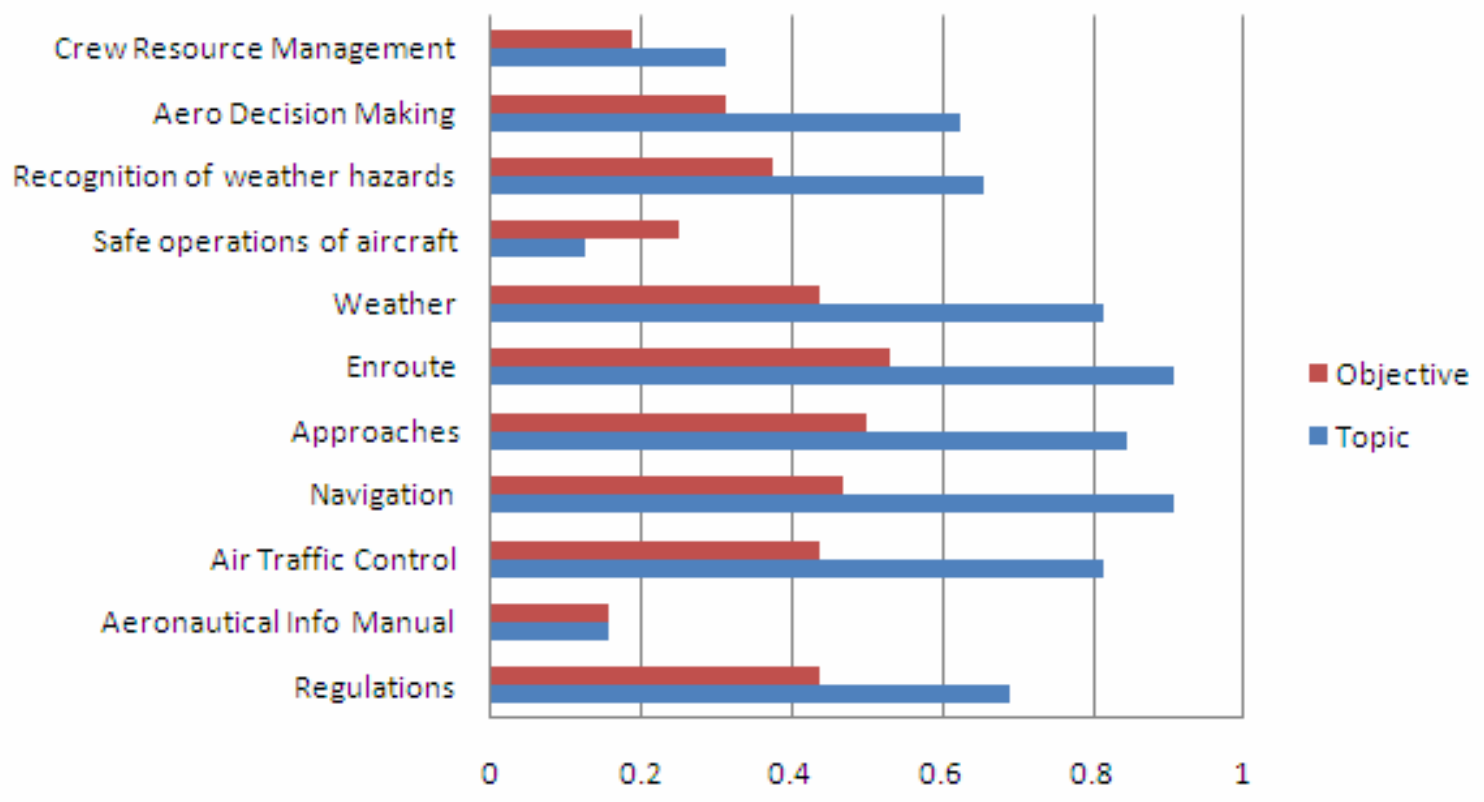

Figure 5. Incidence of objective and content requirements of Title 14 of the CFR Part 141.

\section{Validity and Reliability of Results}

According to Neuendorf (2002), a content analysis study should be valid both internally and externally. Internal validity is "the match-up of a conceptual definition and an operational definition" (Neuendorf, 2002, p. 115) which can be exemplified by a sound measurement scheme. This study utilized an exhaustive coding scheme created with the guidance of a variety of research literature. Further, detailed instructions were made available to coders. "To assess external validity, we may consider the representativeness of the sample...as well as whether the content analysis measurement is true to life" (Neuendorf, 2002, p. 115) which can be proven by a sample that closely matches the population and the replicability of the study. This study utilized purposive sampling, so the attributes of the sample should be very closely related to those of the target population. Also, the detailed coding scheme and instructions should provide a thorough guide for replication of the current study. Further evidence of validity of this study can be found in the "evidence that justifies the treatment of the text" (Krippendorff, 2004, p. 318). In this case, the justification on how to treat the data discovered from this study was established from the research literature.

Neuendorf (2002) noted that reliability, measured among coders, is necessary to be calculated for this type of study because "it must be established that more than one individual can use the coding scheme as a measurement tool, with similar results" (p. 142.) A variety of studies reported acceptable levels of intercoder reliability. Specifically, a Cohen's kappa of greater than .75 was considered reliable (Banjeree, Capozzoli, McSweeney, \& Sinha, 1999; Ellis, 1994; Riffe, Lacy, \& Fico, 2005). The Cohen's kappa calculated for this study was .877 (Olmos, 2007).

\section{DISCUSSION}

The purpose of this study was to examine instrument pilot course syllabi for the inclusion of items deemed essential in the research literature. Also, this study sought to evaluate these syllabi for their inclusion of requisite Title 14 of the CFR Part 141 objectives/topics and their coverage of GPS. Syllabi 
were analyzed for this aforementioned data through the use of content analysis. This study was successful in the collection and analysis of the data necessary to achieve the purpose of this research.

Similarly to other research in the area of the content of syllabi, a large number of instrument pilot course syllabi did not include items that were considered to be essential. While a majority of instrument pilot course syllabi did provide a wide range of objectives and topics that were advertised to be covered throughout the class, it was surprising that subjects that could be considered critical to an instrument pilot, such as the coverage of regulations, basic attitude instrument flying, and the Aeronautical Information Manual, were not omnipresent. However, it would be naïve to believe that simply because a topic is not mentioned in a syllabus it is not covered at any point in the class. Yet the omission of specific subjects does point to a deficiency in the communication between professor and student. It would certainly be understandable how such exclusions could confuse or frustrate a student. Further, as students plan ahead for the semester, they would not be able to foresee the coverage of unmentioned subjects and may believe that such subjects are not important or may not be covered in evaluative tools.

Instrument pilot course syllabi consistently identified the materials that were required for the class. An overwhelming majority utilized texts with the most commonly cited being the Jeppesen Instrument Commercial Manual. Again it was surprising that certain texts, in particular the Federal Aviation Regulations and the Aeronautical Information Manual, were utilized so infrequently. Considering that all but two syllabi specifically required reading assignments, the exclusion of fundamental texts is somewhat troubling. While electronic forms of these important documents are now available from the FAA at no cost, or perhaps students are assumed to already own the material, texts in which reading assignments or expectations exist should still be included on the syllabus.

As might be expected in college courses, exams and quizzes were widely used to determine the grades in instrument pilot courses. Only half of courses identified the instructional method to be used. This is unfortunate as students will not truly know what to expect throughout the academic calendar. Of the syllabi that mentioned instructional methods, most indicated that lecture would be used. The dominance of lecture is unfortunate as this method has often been cited as one that is disliked by students and that it can be marginally effectual if used as the sole means of presentation (DiCarlo, 2009; Tang \& Austin, 2009).

Because students look to the syllabus as their "rule book" for a course, it was encouraging to see that all but one instrument pilot course syllabi included statements on class policies. It was surprising to see that four syllabi omitted an attendance policy although the omission of certain academic rules and standards may be explainable by the inclusion of this information in formal university/college documents or policies. Yet, considering that Title 14 of the CFR Part 141 courses have mandatory attendance, some discussion of this additional obligation should have been mentioned. Also, students that miss Part 141 classes are required to make up such work, yet only slightly more than half of syllabi indicated any kind of makeup policy.

Complete coverage of all Part 141 requirements was limited to five syllabi. Again, it is unlikely that all of these courses actually exclude the coverage of required material however, the omission is problematic for two reasons. First, it could be construed that such courses are, in fact, not fulfilling the requirements under Tile 14 of the CFR Part 141. Second, students are not being given a realistic view of what they are expected learn within the course.

Considering the rapid adaptation of GPS navigation and its increasingly widespread use, it was disquieting that only $71.9 \%$ of syllabi included instruction on this subject. Even more remarkable was the low inclusion rates of RNAV (50.0\%), the general GPS use for approaches (43.8\%), specific RNAV GPS approaches and procedures (37.5\%), WAAS (6.3\%), and RNP (0.0\%). In general, the coverage was somewhat cursory with GPS being incorporated in, on average, slightly more than one class period. No 
syllabi conveyed a comprehensive explanation of GPS. Yet, in all fairness, GPS could be covered more thoroughly in other courses, in aircraft and/or simulators, or simply in the instrument pilot course even though it was not specifically outlined in the syllabus.

\section{CONCLUSION}

Course syllabi serve as a "road map" to students while they progress through a class. These documents also serve as an agreement between the instructor and the student, they are permanent records of course content, and are essential to proving compliance with accrediting agencies. Even in light of the seemingly critical nature of these documents, there is a wide variety of content and quality among them. The fact that few syllabi contain the basic necessary items to properly convey what is to occur in the classroom should serve as a wake-up call to faculty, administration, accreditors, and the FAA. Incomplete syllabi potentially cause irritation, uncertainty, and disorder among students. Furthermore, such deficiencies may continue to passed on as different faculty teach a course unless systematic analysis and change occur to the syllabi.

In sum, aviation faculty must make a greater effort to communicate with their students through syllabi. Faculty should review the literature on syllabi construction, the requirements of Title 14 of the CFR Part 141, and the expectations of the accrediting body responsible for their institution in order to best design their course documents. By filling the gaps in current syllabi, faculty can strengthen their courses and improve student understanding of expectations. Through this enhancement of information, students should have the tools they need to best excel in the class. 


\section{REFERENCES}

Banjeree, M., Capozzoli, M., McSweeney, L., \& Sinha, D. (1999). Beyond kappa: A review of interrater agreement measures. Canadian Journal of Statistics, 27(1), 3-23.

Berg, B. L. (2007). Qualitative research methods for the social sciences (6 ${ }^{\text {th }}$ ed.). Boston: Allyn and Bacon.

Bers, T., Davis, B., \& Taylor, B. (2000). The use of syllabi in assessments: Unobtrusive indicators and tools for faculty development. Assessment Update, 12(3), 4-7.

Bers, T. H., Davis, B. D., \& Taylor, W. (1996). Syllabus analysis: What are we teaching and telling our students? Assessment Update, 8(6), 1-2, 14-15.

Bertorelli, P. (2004). GPS technology. Frederick, MD: AOPA Air Safety Foundation.

Cashwell, C. S., \& Young, J. S. (2004, January). Spirituality in counselor training: A content analysis of syllabi from introductory spirituality courses. Counseling and Values, 48, 96-102.

Casner, S. M. (2004). Flying IFR with GPS: How much practice is needed? (Report No. 2004 212821). Moffett Field, CA: National Aeronautics and Space Administration.

Creswell, J. W. (2008). Research design: Quantitative, qualitative, and mixed methods approaches $\left(3^{\text {rd }}\right.$ ed.). Thousand Oaks, CA: Sage Publications.

Davidson, G., Garton, A., \& Joyce, M. (2003). Survey of ethics education in Australian university schools and departments of psychology. Australian Psychologist, 38(3), 216-222.

DiCarlo, S. (2009). Too much content, not enough thinking, and too little fun. Advances in Physiology Education, 33257-264. doi:10.152/advan.00075.2009.

Drisko, J. W. (2008). How is qualitative research taught at the master's level? Journal of Social Work Education, 44(1). 85-101.

Ellis, L. (1994). Research methods in the social sciences. Madison, WI: WCB Brown \& Benchmark.

Federal Aviation Administration. (2009). FAR/AIM 2010. Newcastle, WA: ASA.

Federal Aviation Administration. (2008). Instrument flying handbook. New York: Skyhorse Publishing.

Habanek, D. (2005). An examination of the integrity of the syllabus. College Teaching, 53(2), 62-64.

Johnson, J. A., \& Ferguson, M. D. (1998). Setting the foundation for effective learning: Utilizing cognitive, affective, and psychomotor domains to establish rigorous performance learning objectives in postsecondary aviation education programs. Collegiate Aviation Review, 16(1), 110.

Imasuen, E. (1999). Campus strategies. Assessment Update, 11(3), 8-9.

Krippendorff, K. (2004). Content analysis: An introduction to its methodology ( $2^{\text {nd }}$ ed.). Thousand Oaks, CA: Sage Publications. 
Lombard, M., Snyder-Duch, J., \& Bracken, C. (2004). A call for standardization in content analysis reliability. Human Communication Research, 30(3), 433-437.

MacQueen, K., McLellan, E., Kay, K., \& Milstein, B. (2008). Codebook development for team based qualitative analysis. Cultural Anthropology Methods, 10(2), 31-36.

Neuendorf, K. A. (2002). The content analysis guidebook. Thousand Oaks, CA: Sage Publications.

Olmos, A. (2007). Cohen's kappa calculator. Retrieved from http://www.olmosantonio.com/Kappa\%20calculator/calculadorakappa.html

Okumus, F., \& Wong, K. (2007). A content analysis of strategic management syllabi in tourism and hospitality schools. Journal of Teaching in Travel \& Tourism, 7(1), 77-97.

Peterson, B. D. (2008). GPS from the ground up. Frederick, MD: AOPA Air Safety Foundation.

Quinnette, R. J. (2002). Training of general aviation pilots on the Global Positioning System. Ed.D. dissertation, Oklahoma State University, United States -- Oklahoma. Retrieved from Dissertations \& Theses: Full Text. (Publication No. AAT 3057301).

Redina-Gobioff, G., Ducher, J., Hess, M., Hogarty, K., Smith, G., Kromrey, J., Lang, T., \& Helmick, I. (2003, November). A content analysis of the common core syllabi. Paper presented at the meeting of the Florida Educational Research Association, Orlando, FL.

Riffe, D., Lacy, S., \& Fico, F. (2005). Analyzing media messages using qualitative content analysis in research ( $2^{\text {nd }} \mathrm{ed}$.). New York: Taylor and Francis Group.

Slattery, J., \& Carlson, J. (2005). Preparing an effective syllabus. College Teaching, 53(4), 159-164.

Steuemagle, J. (n.d.). GPS for IFR. Retrieved from http://www.aopa.org/asf/publications/inst_reports2.cfm?article $=4143$

Tang, T., \& Austin, M. (2009). Students' perceptions of teaching technologies, application of technologies, and academic performance. Computers \& Education, 53(4), 1241-1255. doi:10.1016/j.compedu.2009.06.007.

University Aviation Association. (2008). Collegiate aviation guide (5 $5^{\text {th }}$ ed.). Auburn, AL: Author.

Wasley, P. (2008). Syllabus. Chronicle of Higher Education, 54(28), A9

Weber, R. P. (1990). Basic content analysis ( $2^{\text {nd }}$ ed.). Newbury Park, CA: Sage Publications.

Weston, C., Gandell, T., Beauchamp, J., McAlpine, L., Wiseman, C., \& Beauchamp, C. (2001). Analyzing interview data: The development and evolution of a coding system. Qualitative Sociology, 24(3), 381-400.

White, G. W. (2004). Business information courses in LIS programs: A content analysis. Journal of Business \& Finance Librarianship, 20(2), 3-15. 